\title{
Genetic manipulation: guidelines issued
}

\author{
The NIH ground rules for genetic manipulation experiments may not mark the end of an \\ unprecedented debate within the scientific community. Colin Norman reports from Washington
}

\begin{abstract}
A FTER two years of controversy and uncertainty, the National Institutes of Health $(\mathrm{NIH})$ last week issued a complex set of guidelines governing the use of a powerful new technique for manipulating genes in living organisms. The guidelines establish safety rules for experiments which may revolutionize biology, but which also provide man with unprecedented ability to alter the characteristics of living things. They are, however, far from being the final word on whether, and under what circumstances, such research should be allowed to go ahead, for they are already being overtaken by events in some places.
\end{abstract}

On July 7, for example, the City Council in Cambridge, Mass., will vote on a resolution, proposed by the Mayor, which would ban for two years all such experiments at Harvard and MIT. And months of bitter debate at the University of Michigan have resulted in the adoption of regulations there which are more strict than those issued by NIH last week. The focus of the debate is clearly shifting from Washington into the university communities where the research will take place.

Nevertheless, the NIH guidelines will provide important ground rules for genetic manipulation experiments in many institutions, and their impact will extend far beyond the borders of the United States, for they are likely to influence the establishment of guidelines in many other countries. They have been developed by an extraordinary process of self-regulation by the scientific community.

The process began in 1973, when scientists familiar with the nascent technique began to worry about potential hazards associated with its use. Their concerns led a committee of the National Academy of Sciences to issue a public statement in July 1974, urging scientists around the world to defer two types of experiments until the hazards have been defined. The moratorium lasted until last February, when it was partly replaced by general guidelines recommended by an international group of geneticists which met at Asilomar, California. Then an NIH advisory committee, consisting of scientists, took centre stage. It laboured hard during most of last year trying to cast the Asilomar guidelines into more specific rules, completing its task by hammering out a set of complex proposals last December. The proposals went to NIH Director Donald S. Fredrickson, who called a public meeting to discuss them, solicited the views of numerous scientists and non-scientists, and asked the advisory committee to reconsider some of its suggestions. The guidelines issued last week represent Fredrickson's distillation of the conflicting advice presented to him.

They differ a little in detail, but not in philosophy, from the recommendations of the advisory committee. They will allow most planned experiments to go ahead, albeit under strict safety controls, outlawing only a handful of the more hazardous types of experiments. They are, however, stricter than the Asilomar guidelines, a fact which Fredrickson suggested means that "the research will go forward in a manner responsive and appropriate to hazards that may be realised in the future". And Dr DeWitt Stetten, Deputy NIH Director for Science and chairman of the advisory committee, argued last week that "the issuance of the guidelines is in no sense an opening of the floodgates, rather it is a closing of the leaks (in the Asilomar guidelines)".

$\mathrm{Be}$ that as it may, the guidelines are not even NIH's final say on the matter. Their publication falls under the terms of the National Environmental Policy Act, which means that NIH must prepare an assessment of the potential impact of the research on the environment. A draft assessment should be ready by September, and since it will be opened up for public comments before being cast in final form, another round of discussion of the risks and benefits of the research is in store. In the meantime, the guidelines will take effect, governing NIH's support of the research.

\section{New dimension}

Why have the guidelines taken so long to produce, and caused so much strife? The answer is that the research offers a spectacular mix of potential benefits and possible hazards, and it opens up an entirely new dimension in biology. The experiments consist, in short, of snipping genes from the DNA of any organism and splicing them into the DNA of another, perhaps entirely unrelated, organism. The resulting molecule-a recombinant DNA moleculeis copied (cloned) each time the new host reproduces, producing large quantities of the transplanted genes. The technique offers a powerful tool for probing the working of genes and their arrangement in complex organisms and, more distantly, it may offer a means of constructing special micro-organisms for a variety of medical, commercial and industrial uses.

But the worry is that the technique allows biologists to breach genetic barriers between species which have evolved over thousands of years. In short, it allows biologists to by-pass the processes of evolution. More specifically, foreign genes inserted into an organism may cause that organism to behave in a dangerous, and perhaps unpredictable, manner. The guidelines thus seek to ensure that micro-organisms bearing transplanted genes are contained in the laboratory.

They spell out our levels of physical containment to be used in such experiments, designated $\mathrm{P} 1$ to $\mathrm{P} 4$, ranging from use of standard microbiological techniques (P1) to the use of specially equipped facilities akin to biological warfare laboratories (P4). And, as a second line of defence, they spell out three levels of biological containment, EK1 to EK3, which must be used for experiments involving the insertion of genes into a strain of the common gut bacterium $E$. coli-the organism which will be used for most experiments. The levels are as follows:

-EK1-use of standard E. coli $\mathrm{K} 12$, a laboratory strain of $E$. coli which has been used for genetic experiments for decades. Foreign genes are inserted into the bacterium by splicing them into a plasmid (a ring of bacterial DNA which reproduces independently from the bacterium's chromosomes) and reintroducing the recombinant into the bacterium, or by splicing them into the DNA of a bacteriophage which then infects $E$. coli K12.

EK2-the use of specially mutated strains of $E$. cali or bacteriophage which, according to laboratory tests, are virtually incapable of surviving outside the laboratory so that the recombinant DNA will have less than 1 in $10^{-8}$ chances of surviving in the natural environment.

EK3-the same as EK2 except that the survivability has been tested in animals, plants and other environments.

The guidelines assign specific physical and biological safety levels to various types of experiments on the basis of their potential hazards (see box). They 
also spell out safety rules for experiments involving recombinants formed by splicing genes into the DNA of animal viruses, which are then grown in cell cultures to provide multiple copies of the foreign genes. The final guidelines alter some of the containment levels proposed by the advisory committee, but no substantial alterations have been made.

\section{Cautious approach}

How did Fredrickson arrive at his final decision when confronted with such a wealth of conflicting advice? His first, and most fundamental, consideration was simply whether the research should be allowed to go ahead at all, in view of the potential hazards. The majority of the commentators on the guidelines recommended that it should, but he was advised to take an extremely cautious approach by two of the most eminent of the commentators, neither of whom intends to conduct experiments with recombinant DNA.

Dr Robert Sinsheimer, chairman of the Department of Biology at California Institute of Technology, argued in a letter to Fredrickson that the experiments present a serious hazard if they breach the genetic barrier between higher organisms (eukaryotes) and lower organisms (prokaryotes). "One need not continue to spin out potential horror stories", he wrote, "the point is that we will be perturbing, in a major way, an extremely intricate ecological interaction which we understand only dimly". As for the guidelines themselves, Sinsheimer stated: "I cannot believe that under these proposed guidelines the organism can be contained. If the work is going on in a hundred laboratories about the United States, performed by technicians, graduate students, etc., the organism will inevitably escape-and will enter into the various ecological niches known to be inhabited by $E$. coli." He therefore proposed that all work with recombinant DNA should be performed under maximum containment conditions at a single institution in the United States, and that there should be an intensive effort to seek a microorganism more suitable than $E$. coli for the work.

The other eminent, though more flamboyant, critic of the guidelines, Erwin Chargaff of Columbia University, recommended that all work on recombinant DNA should be halted for at least two years to allow time for the hazards to be assessed. Chargaff asked, in a letter published in Science, "Have we the right to counteract, irreversibly, the evolutionary wisdom of millions of years, in order to satisfy the ambition and the curiosity of a few scientists?"

The advisory committee did not consider Sinsheimer's or Chargaff's pro-

\section{Guidelines in detail}

The guidelines define four levels of physical containment, designated, in order of increasing stringency, $\mathrm{P} 1$ to $\mathrm{P} 4$, and three levels of biological containment, EK1 to EK3, and assign experiments to them on the basis of potential risk. The following is a summary of containment levels specified for various sources of DNA.

a. Shotgun experiments using $E$. coli as the host

Non-embryonic primate tissue

Embryonic primate tissue or germ line cells

Other mammals

Birds

Cold blooded vertebrates, non-embryonic embryonic or germ line

If vertebrate produces a toxin

Other cold blooded animals and lower eukaryotes

If Class 2 pathogen*, produces a toxin, or carries a pathogen

Plants

$\mathrm{P} 3+\mathrm{EK} 3$ or $\mathrm{P} 4+\mathrm{EK} 2$

$\mathrm{P} 3+\mathrm{EK} 2$

$\mathrm{P} 3+\mathrm{EK} 2$

$\mathrm{P} 3+\mathrm{EK} 2$

$\mathrm{P} 2+\mathrm{EK} 2$

$\mathrm{P} 2+\mathrm{EK} 1$

$\mathrm{P} 3+\mathrm{EK} 2$

$\mathrm{P} 2+\mathrm{EK} 1$

Prokaryotes that exchange genes with $E$. coli

Class 1 agents (non-pathogens)

Low risk pathogens (for example, enterobacteria)

Moderate risk pathogens (for example, S. typhi)

Higher risk pathogens

Prokaryotes that do not exchange genes with $E$. coli

Class 1 agents

Class 2 agents (moderate risk pathogens)

Higher pathogens

$$
\begin{aligned}
& \mathrm{P} 1+\mathrm{EK} 1 \\
& \mathrm{P} 2+\mathrm{EK} 1 \\
& \mathrm{P} 2+\mathrm{EK} 2 \\
& \text { banned }
\end{aligned}
$$

$\mathrm{P} 2+\mathrm{EK} 2$ or $\mathrm{P} 3+\mathrm{EK} 1$ $\mathrm{P} 3+\mathrm{EK} 2$

banned

In all above cases, if DNA is at least $99 \%$ pure before cloning and contains no harmful genes, either physical or biological containment levels can be reduced one step.

b. Cloning plasmid, bacteriophage and other virus genes in $E$. coli

Animal viruses

If clones free from harmful regions

Plant viruses

$99 \%$ pure organelle DNA, Primates other eukaryotes

Impure organelle DNA: shotgun conditions apply.

$\mathrm{P} 4+\mathrm{EK} 2$ or $\mathrm{P} 3+\mathrm{EK} 3$
$\mathrm{P} 3+\mathrm{EK} 2$
$\mathrm{P} 3+\mathrm{EK} 1$ or $\mathrm{P} 2+\mathrm{EK} 2$
$\mathrm{P} 3+\mathrm{EK} 1$ or $\mathrm{P} 2+\mathrm{EK} 2$
$\mathrm{P} 2+\mathrm{EK} 1$

Plasmid or phage DNA from hosts that exchange genes with E.coli

If plasmid or phage genome does not contain harmful genes or if DNA segment $99 \%$ pure and characterised

Otherwise, shotgun conditions apply.

Plasmids and phage from hosts which do not exchange genes with $E$. coli

Shotgun conditions apply, unless minimal risk that recombinant will increase pathogenicity or ecological potential of the host, then

$\mathrm{P} 2+\mathrm{EK} 2$ or $\mathrm{P} 3+\mathrm{EK} 1$

NB. cDNAs synthesised in vitro from cellular or viral RNAs are included in above categories.

c. Animal virus vectors

Defective polyoma virus + DNA from non-pathogen

Defective polyoma virus + DNA from Class 2 agent

P3

P4

If cloned recombinant contains no harmful genes and host range of polyoma unaltered, teduce to

Defective SV40+DNA from non-pathogens

If inserted DNA is $99 \%$ pure segment of prokaryotic DNA lacking toxigenic genes, or a segment of eukaryotic DNA whose function has been established and which has previously been cloned in a prokaryotic host-vector system, and if infectivity of SV40 in human cells unaltered

Defective SV40 lacking substantial section of the late region + DNA from non-pathogens, if no helper used and no virus particles produced

Defective SV40+DNA from non-pathogen can be used to transform established lines of non-permissive cells under P3 provided no infectious particles produced. Rescue of SV40 from such cells requires

d. Plant host-vector systems

P2 conditions can be approximated by insect-free greenhouses, sterilization of plant, pots, soil and runoff water, and use of standard microbiological practice.

P3 conditions requirc use of growth chambers under negative pressure and routine fumigation for insect control.

Otherwise, similar conditions to those prescribed for animal systems apply.

*Classes for pathogenic agents as defined by the Center for Disease Control. 
posals during its public meetings, but Fredrickson alluded to them in a lengthy statement published along with the guidelines. Recognising that the breaching of genetic barriers might pose a hazard, Fredrickson nevertheless argued that the research can be controlled so that it is carried out safely. Noting that "the international scientific community . . . has indicated a desire to proceed with research in a conservative manner", and that "most of the considerable public commentary on the subject, while urging caution, has also favoured proceeding", Fredrickson pointed out that there is, in any case, no way to prohibit the research throughout the world. "There is," he added, "no reason to attempt it."

Having decided that there should be no flat proscription on the research, Fredrickson turned to some of the chief concerns raised by the critics of the guidelines. The most prominent concern arises from the fact that most work with recombinant DNA will take place with the $E$. coli $\mathrm{K} 12$ bacterium. Since $E$. coli is a common inhabitant of the human gut, many observers have considered it a dangerous choice for the research. In particular, a group of scientists from the Boston area urged that a different host for transplanted genes be developed, and that the use of $E$. coli be phased out as swiftly as possible.

Fredrickson argues, however, that since the bacterium has been used for decades as the geneticists' workhorse, there is extensive knowledge of its behaviour and, moreover, there is good evidence that it is unlikely to survive for long in the environment in competition with wild strains of $E$. coli. In other words, $E$. coli $\mathrm{K} 12$ itself provides a level of biological containment. "I believe that because of this experience, $E$. coli $\mathrm{K} 12$ will provide a host-vector system that is safer than other systems", Fredrickson argued, and he declined to set a limit on when it should be phased out of the research.

Another area of concern with the proposed guidelines centred on how they should be implemented, and that section has been extensively revised. The guidelines strictly apply only to research supported by NIH, and investigators must comply with them before they can receive a grant. Some commentators suggested that principal investigators be required to obtain informed consent from all laboratory personnel before proceeding with recombinant DNA experiments, but Fredrickson opted instead for a requirement that the investigators simply inform all laboratory workers of the real and potential hazards associated with the experiments.

The guidelines also require that each institution where recombinant DNA experiments will be conducted should establish a biohazards committee, to ensure that facilities meet specified requirements, training is adequate and so on. The advisory committee had firmly recommended that such committees should not be responsible for determining the containment conditions for specific experiments, but Fredrickson deleted that prohibition, leaving the matter up to individual institutions.

A final point concerning implementation which is clearly worrying many people is that the guidelines do not apply to industry. Early last month, however, Fredrickson briefed officials from various industries on the guidelines and received from them expressions of support for their intent and their general provisions. Some officials expressed reservations about specific items, however, such as the provision prohibiting large-scale experiments with recombinant DNA, and the Pharmaceutical Manufacturers' Association has decided to convene a committee to review whether the guidelines are applicable to the drug industry.

\section{Effect of guidelines}

Now that these guidelines have been issued, how do they affect academic scientists conducting, or hoping to conduct, recombinant DNA experiments? First, they specify that many experiments should use EK2 or EK3 biological containment, and until crippled micro-organisms which meet those criteria are available, such experiments should not be conducted. The advisory committee which drafted the guidelines is responsible for certifying whether crippled strains meet the criteria.

A strain of $E$. coli produced by Roy Curtiss of the University of Alabama (called $\psi 1776$ ) has been proposed as an EK2 system with two specific plasmids (pSC101 and Col El-kan). Curtiss, who has built many crippling mutations into the bacteria in an effort which took the best part of a year, has provided the committee with reams of data on its survivability. Last month, a subcommittee voted unanimously that the strain meets the EK2 specifications, and the full committee is expected to approve it in the next few weeks. That would pave the way for many experiments.

But a confusing situation has developed with respect to two other candidate EK2 strains. At its last meeting in April, the committee approved a strain of bacteriophage lambda, developed by Philip Leder of NIH as an EK2 strain. But a subcommittee which met last month to consider a second candidate strain, developed by Fred Blattner at the University of Wisconsin, was divided on a matter which affects both strains. In short, two subcommittee members refused to endorse the use of either phage as an EK2 system unless they are used in conjunction with crippled bacteria. The full committee will take up that thorny issue when it next meets in September. Curtiss's E. coli strain, incidentally, is resistant to infection by phage $\lambda$.

Many of the objections and reservations which critics have levelled at the guidelines are now beginning to crop up in local debates in and around the universities where the research will be conducted. In that regard, the situation brewing in Cambridge, Mass., may be an indication of things to come. It began quietly a few months ago, when some researchers at Harvard proposed that a laboratory, meeting $\mathrm{P} 3$ requirements, be established in the Harvard Biology Labs. The facility, which would cost some $\$ 350,000$, would have involved converting some existing laboratory space, and the intent was to undertake a variety of work in it, including some recombinant DNA experiments.

The proposal met with opposition within Harvard, however, largely because the biology labs are old, infested with cockroaches and with a species of ant which has so far evaded attempts at eradication. In short, critics suggested that the building is unsuitable for a P3 facility. Their criticisms broadened into an assault on the proposal to conduct recombinant DNA experiments at Harvard, however, and the dispute spilled over into the city when the matter was reported at length in Boston's weekly newspaper.

Approval of the laboratory by the Harvard authorities was all but assured, since the concept had been endorsed by a biohazards committee, Harvard's Committee on Research Policy, and the Dean of Arts and Sciences. But, when he read about the dispute in the newspapers, Cambridge city Mayor Alfred Velucci stepped in. He called a council meeting on June 23 -ironically the day the NIH guidelines were issued-to discuss the matter, and a string of scientists testified about the potential hazards and benefits of recombinant DNA research. By all accounts, the atmosphere was highly charged, and there was considerable heated discussion.

The matter has now gone well beyond the issue of whether the laboratory should be built, however, for Velucci has introduced a resolution which would prohibit all recombinant DNA experiments in Cambridgeeven those deemed to have minimal risk-for two years. The council will vote on the resolution on July 7, and the outcome will be closely watched around the country. 